\title{
Wind Turbine Clutter
}

\author{
Beatriz Gallardo-Hernando, Félix Pérez-Martínez \\ and Fernando Aguado-Encabo \\ Technical University of Madrid (UPM) and Spanish Meteorological Agency (AEMET)
}

Spain

\section{Introduction}

The use of wind farms to generate electricity is growing due to the importance of being a renewable energy source. These installations can have over a hundred turbines of up to 120 $\mathrm{m}$ height each. Wind farm installations relatively near to radar systems cause clutter returns that can affect the normal operation of these radars. Wind turbines provoke clutter reflectivity returns with unpredictable Doppler shifts.

Wind turbines exhibit high radar cross sections (RCS), up to $1000 \mathrm{~m}^{2}$ in some instances, and then, they are easily detected by radars. A typical wind turbine is made up of three main components, the tower, the nacelle and the rotor. The tower is a constant zero velocity return that can be suppressed by stationary clutter filtering. Unlike the tower, the turbine nacelle RCS is a function of the turbine yaw angle, and then, the radar signature will depend on this factor. Moreover, most wind turbines present curved surface nacelles which will scatter the energy in all directions and so the variability of the RCS is prominent. In addition, the rotor makes the blades move fast enough to be unsuppressed by conventional clutter filtering.

In this chapter, we will examine the characteristics of wind turbine clutter in great detail. For this purpose, we will use examples derived from real experimental data. After describing the experimental data gathered, we will perform several studies.

First of all, a complete statistical characterization of the experimental data will be accomplished. This statistical study will show the distinctive properties of this variety of clutter and then, it will give us clues for its correct detection, as every detection theory must rely on statistics. In this case we will study isolated turbines, so that the obtained characteristics will be accurate. After that, we will make an extensive frequency analysis. Different configurations will be studied, with variations such us the number of turbines, the yaw angle or the radar dwell time. This will show various wind turbine clutter situations that most affected radar systems have to deal with.

Finally, some mitigation techniques that have been published to date will be reviewed. Their main purposes, techniques and results will be analyzed and illustrated with descriptive examples.

\section{Wind turbine clutter}

\subsection{Wind power}

Wind power has proved to be one of the most profitable energy sources both in terms of economy and ecology. In fact, many countries have launched programs in order to deploy 
wind turbines as alternative sources of energy, trying to tackle the climate change as well as the increasing oil costs. As it can be seen in Fig. 1, wind energy production has been exponentially increasing (World Wind Energy Association, 2009) since the early 90s.

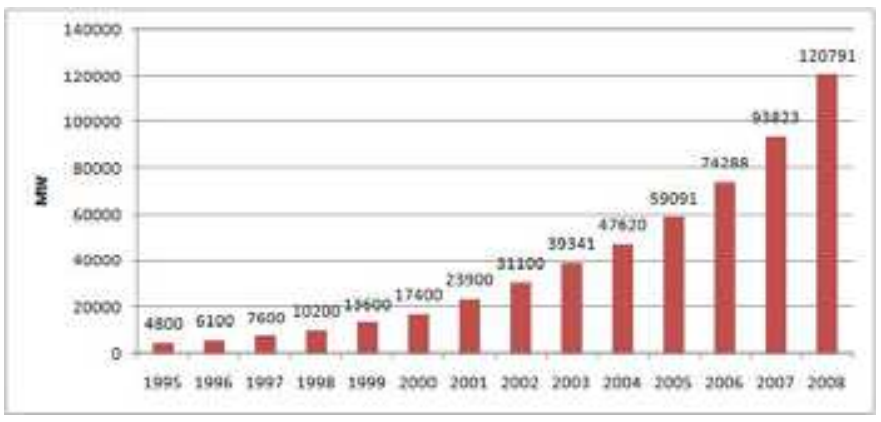

Fig. 1. Evolution of the wind power installed in the world.

Traditionally, Europe has leaded the wind energy market, with $70 \%$ of the sales by 2000 (Hatziargyriu \& Zervos, 2001). However, the wind energy capacity has been promoted all over the world, and countries such as China or India are now using this technology to produce large amounts of electrical energy. USA is currently the largest wind power market, followed by Germany and Spain, Fig. 2 (World Wind Energy Association, 2009). With respect to penetration rates, this power provides $19 \%$ of the total energy consumed in Denmark, $11 \%$ in Spain and Portugal, 6\% in Germany and 1\% in USA (Thresher \& Robinson, 2007). In terms of growth, world wind generation capacity more than quadrupled between 2000 and 2006. Wind farms will continue its expansion, as it is expected that within the next decades wind energy will occupy $20 \%$ of the total annual power consumed both in Europe and USA (Thresher \& Robinson., 2007). As a consequence, the impact of wind turbine clutter on radars is going be more and more important.

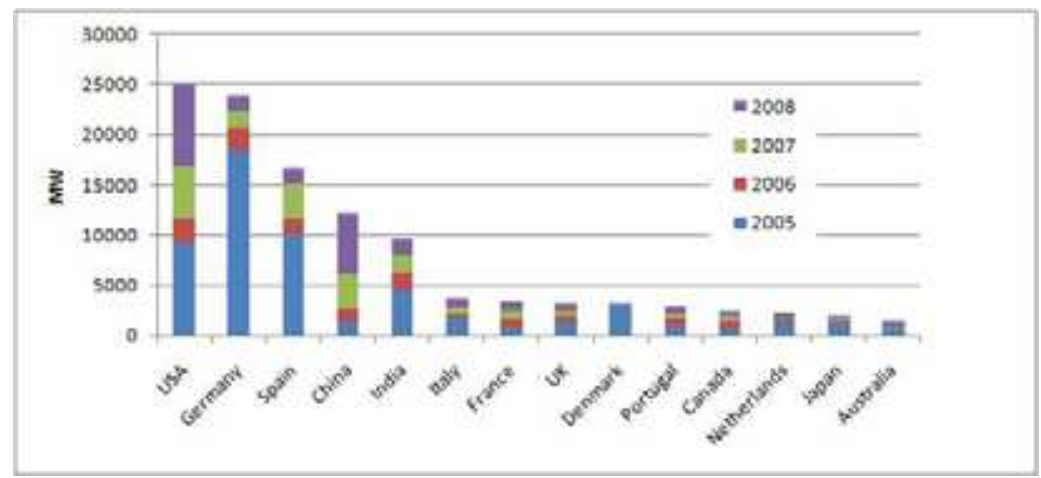

Fig. 2. Cumulative wind power capacity in the world.

\subsection{Effects of wind turbines on radar systems}

A typical wind turbine is made up of three components, the tower, the nacelle and the rotor. The tower means a constant zero velocity return than can be easily minimized by means of an appropriate clutter cancellation. Unlike the tower, the turbine nacelle radar cross section 
(RCS) is a function of the turbine yaw angle and then, the radar signature will depend on this factor. More over, most wind turbines present curved surface nacelles which will scatter the energy in all directions and so, will increment the variability of the RCS (Poupart, 2003). Some studies conclude (Greving, 2008a) that the traditional RCS scheme is not applicable for objects on the ground and, therefore, it is not a useful parameter for the definition of safeguarding distances of wind farms to radars. Besides, the rotor makes the blades move fast enough to be unsuppressed by stationary clutter filtering, with maximum angular velocities between 30 and $50 \mathrm{rpm}$ (Freris, 1992). To sum up, the main effects wind turbines have on radars are the following (Perry \& Biss, 2007):

- The magnitude of the reflections from the wind turbine can cause radar receivers to be driven to saturation. In fact, typical tower heights reach $100 \mathrm{~m}$, with blades from 30 to $50 \mathrm{~m}$ long, see Table 1 (Gamesa, 2009). Some studies address this problem and propose stealth technologies to mitigate this effect. The solutions involve both shaping and development of absorbing materials (Matthews et al., 2007)

\begin{tabular}{|l|c|c|c|}
\hline Model & G58 & G83 & G90 \\
\hline Turbine rating (kW) & 850 & 2000 & 2000 \\
\hline Blade length $(\mathrm{m})$ & 28.3 & 40.5 & 44 \\
\hline Tower height $(\mathrm{m})$ & $44-71$ & $67-78$ & $67-100$ \\
\hline Rotation rate $(\mathrm{rpm})$ & $14.6-30.8$ & $9-19$ & $9-19$ \\
\hline Max Tip speed (m/ s) & 91 & 80.5 & 87.5 \\
\hline
\end{tabular}

Table 1. Typical Wind Turbine parameters.

- The rotation movement of blades cause Doppler shifts. The velocity of a blade depend on the distance from the centre, therefore, there is an increasing Doppler shift from the centre to the tip of the blade. This spectrum can fall within the limits of some radars or exceed them.

These effects result in various situations in different radars.

- For primary surveillance radars, air traffic control and air defence (Jackson, 2007), wind turbine effects include clutter, increased number of unwanted returns in the area of wind farms; desensitisation, reduced probability of detection for wanted air target; and a consequent loss of wanted target plotting and tracking. In conclusion, they provoke higher probability of false alarm and lower probability of detection.

- In weather radars (Vogt et al., 2008), the clutter, signal blockage and interference may cause the misidentification of thunderstorm features and meteorological algorithm errors such us false radar estimates of precipitation accumulation, false tornadic vortex and mesocyclone signatures and incorrect storm cell identification and tracking.

- Monopulse secondary radars performance is also affected by the presence of wind turbines (Theil \& van Ewijk, 2007). The azimuth estimate obtained with the monopulse principle can be biased when the interrogated target emits its response when partially obscured by an large obstacle such as a wind turbine.

\section{Radar signature of wind turbine clutter}

\subsection{Experimental data}

In the experiments, made with the aid of the Spanish weather C-band radar network, we gathered data in normal and spotlight operation modes. In the first case, the aim is to 
calculate the Doppler spectrum in two ways: for each range gate, for a specific azimuth angle; and for each azimuth angle, for a specific range gate. This will show the variations of the wind turbine clutter Doppler spectrum as functions of range and azimuth angle. This spectrum is expected to have specific features which would aid the identification and mitigation of these clutter returns. In the second case, spotlight operation mode, the data are collected from a particular cell, known to experiment wind turbine clutter and so defined by specific range and azimuth angle. That is to say, the radar dish is stationary and a large and contiguous set of time series is collected. Thus, the information about temporal evolution of the amplitude of the signal and its Doppler spectrum can be easily extracted. These experiments allow us to do a detailed examination of the spectral characteristics and statistics of the wind turbine clutter signal.

All data were taken from a C-band weather radar near Palencia, Spain. Up to three different wind farms can be seen in a narrow sector between 30 and $45 \mathrm{~km}$ away from the radar. The main wind farm is composed by 54 wind turbines model G-58 (Gamesa, 2009), which provide an average power of $49300 \mathrm{~kW}$. It was a clear day, so there weren't interfering weather signals. In the following figure we can distinguish the three wind farms.

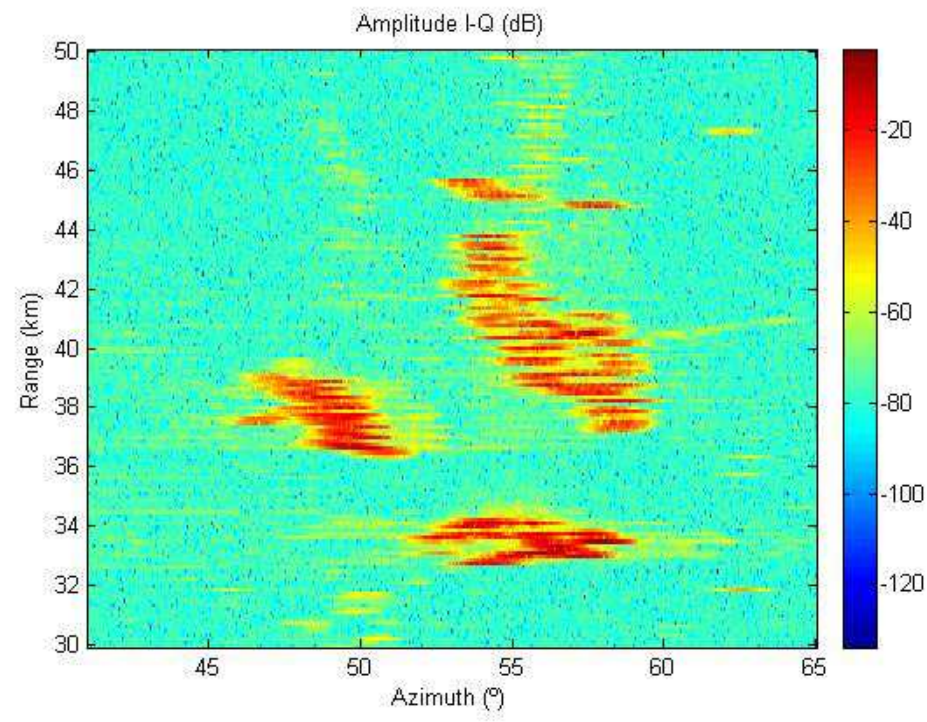

Fig. 3. PPI representation of the data under study.

The turbines layout within the wind farm let the radar resolve the different rows. It is usual to maintain a minimum distance between turbines (Jenkins, 1993) because when a wind turbine extracts energy from the wind it creates a wake of slower, more turbulent air which will negatively impact on the performance of adjacent turbines. This spacing is usually set from five to eight times the blade diameter, that is, about $200 \mathrm{~m}$. Therefore, with a radar range resolution of $125 \mathrm{~m}$ it is possible to resolve different turbines in range. However, azimuth resolution does vary with the distance and most of the times two or more turbines will occupy the same resolution cell. 


\subsection{Scanning radar}

By calculating the Doppler spectrum, defined as the power weighted distribution of radial velocities within the resolution volume of the radar (Doviak \& Zrnic, 1984), for each azimuth angle, for a particular range gate, the spectral content versus the azimuth angle can be studied. I-Q radar data were gathered with the slowest antenna velocity, the lowest elevation angle (the most affected by the presence of wind farms) and the highest pulse repetition frequency (PRF). See Table 2 for detailed radar parameters. The spectral content of several range bins has been studied using a Short-time Fourier Transform (STFT) of partially overlapped time sectors to build a spectrogram. A Hamming window was used in order to diminish windowing effects.

An example has been represented in Fig. 4 (Gallardo-Hernando et al. 2008b). There was an isolated wind mill in the selected range gate, so, the spectrum is located at a very specific azimuth angle. This spectrum is extremely wide, as some of its components seem to be overlapped.

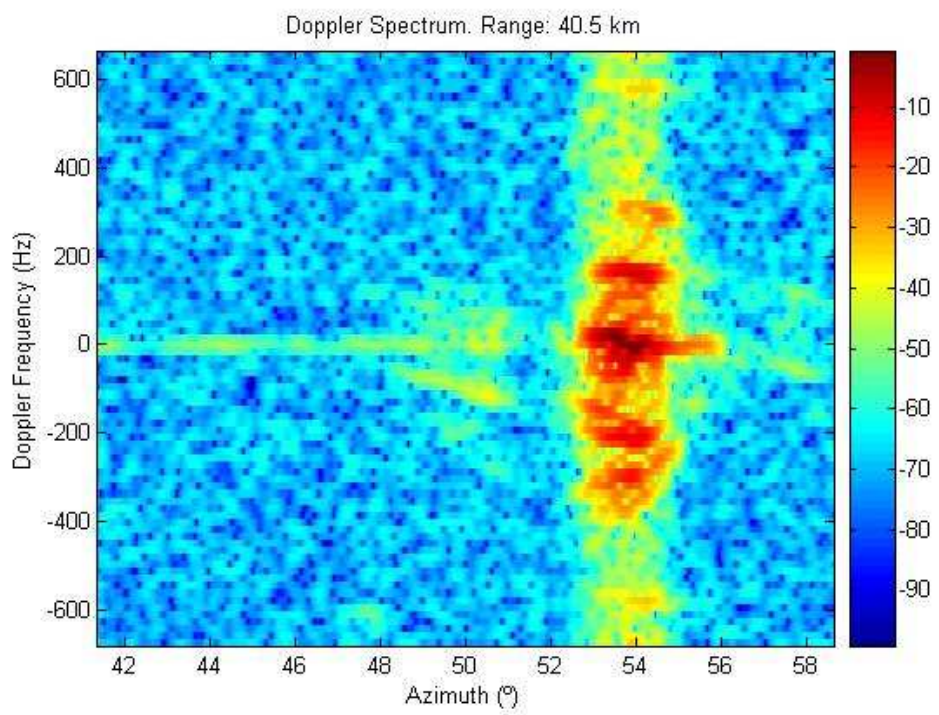

Fig. 4. Doppler spectrum versus azimuth angle.

\begin{tabular}{|l|c|}
\hline Frequency & $5500 \mathrm{MHz}$ \\
\hline Beam width & $0.8^{\circ}$ \\
\hline Power & $250 \mathrm{~kW}$ \\
\hline Antenna gain & $43 \mathrm{dBi}$ \\
\hline Pulse repetition frequency (PRF) & $1300 \mathrm{~Hz}$ \\
\hline Elevation angle & $0.5^{\circ}$ \\
\hline Antenna velocity & $12^{\circ} / \mathrm{s}$ \\
\hline Pulse length & $0.5 \mu \mathrm{s}$ \\
\hline
\end{tabular}

Table 2. Scanning radar parameters. 
The spectrum of two different turbines in the same range bin is plotted in Fig. 5. The Doppler frequency shift is different for each turbine for two reasons. First, the rotors can have different velocities of rotation. Second, although the turbines were rotating at the same velocity, the yaw angle could be different and so the radial velocity.

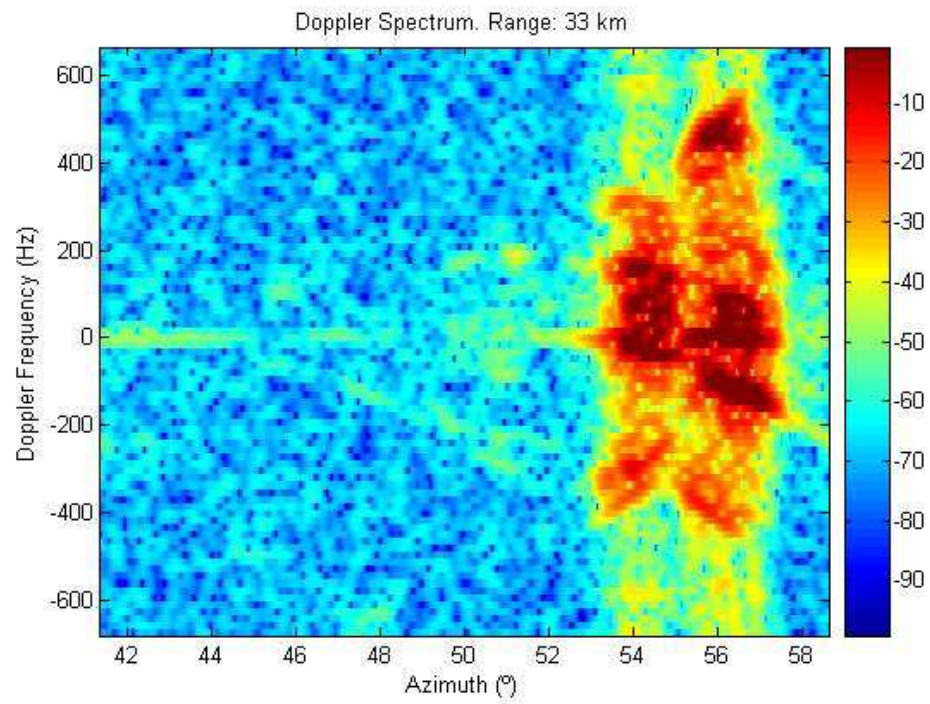

Fig. 5. Doppler spectrum of two adjacent wind turbines.

Fig. 6 shows a similar variation of the Doppler spectrum, now as a function of range. This spectrum is also extremely wide, and it obviously appears at every range gate with wind turbines located in.

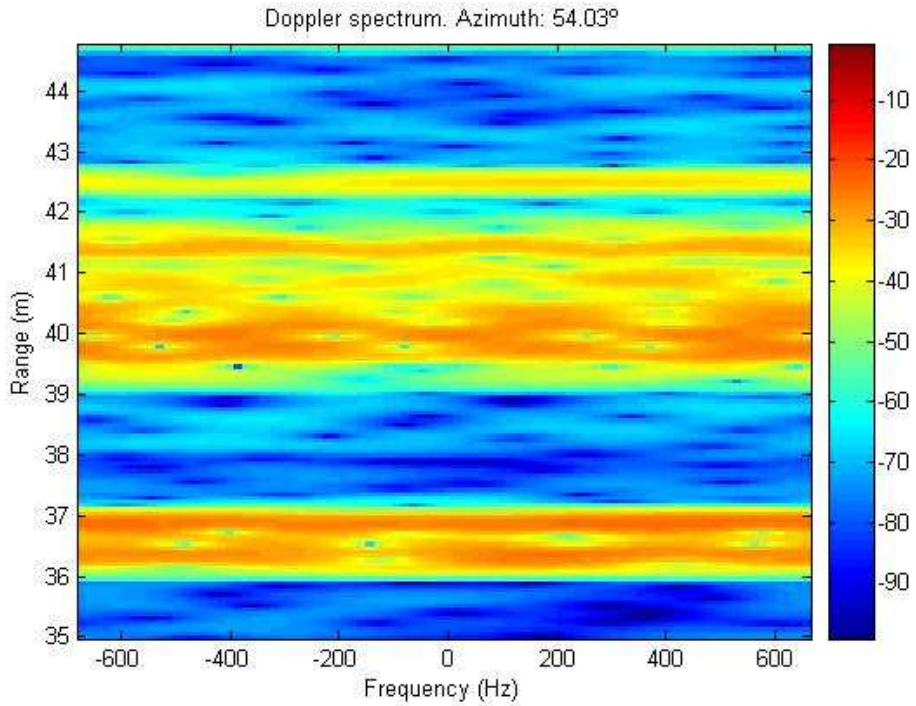

Fig. 6. Doppler spectrum calculated on the $54^{\circ}$ azimuth bin. 


\subsection{Spotlight radar}

In this operation mode, defined in (Isom et al., 2008), a large set of time series was collected while the radar dish was stationary and the azimuth angle defined to get data from the wind farm, 54.03․ Radar parameters are similar to those of Table 2, but for the radar antenna, zero velocity.

Fig. 7 shows the variation of the signal amplitude versus time. It shows a clear periodicity that is supposed to be caused by the motion of blades. Later on this periodicity will be studied, see section 3.3. The noise level seems to be $20 \mathrm{~dB}$ under the signal and the effect of target scintillation is clearly seen.

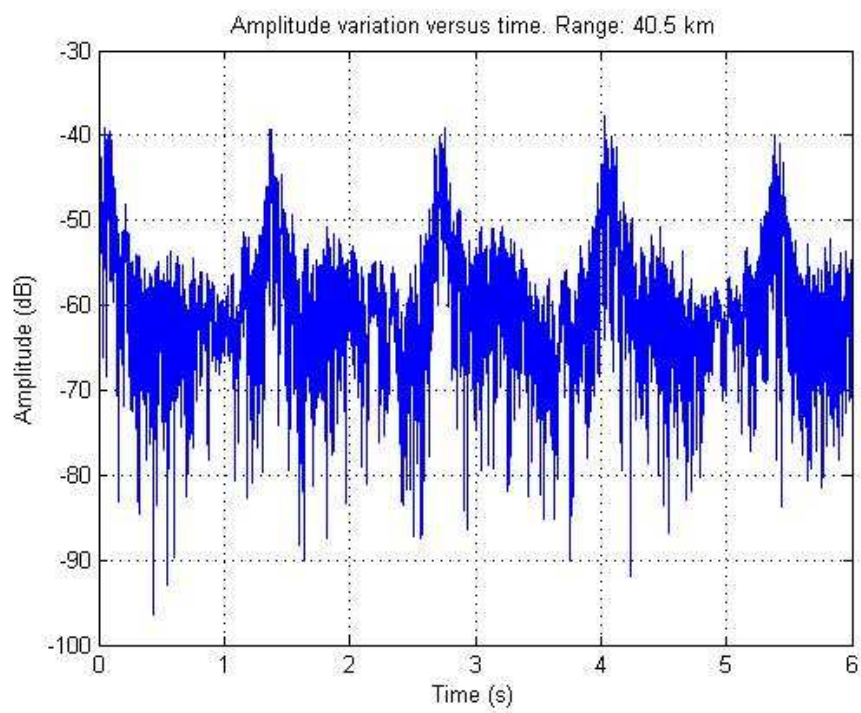

Fig. 7. Amplitude variation at $42.5 \mathrm{~km}$ bin versus time.

A frequency transform was made to calculate the Doppler spectrum. Fig. 8 shows the Doppler spectrogram in time, and the same periodicities seen in Fig. 7 seem to be here. The echo of the blades is characterized by short flashes, which occur when one blade is orthogonal with respect to the propagation direction of the transmitted signal (GallardoHernando et al., 2008b). Once again, the spectrum is spread all over Doppler frequencies, and so, we cannot assure which components are moving tow ards or aw ay from the radar.

Then, there are five very intense Doppler returns in Fig. 8. These flashes are separated approximately 1.33 seconds. By considering a three-blade wind turbine, this period means than one blade takes over 4 seconds to do an entire rotation of $360^{\circ}$, that is to say, the angular velocity of the blades is estimated to be $15 \mathrm{rpm}$. The reason why negative Doppler shifts (blades going down) are less powerful lies in the elevation angle, the differences of RCS between blade sides, and also in a possible shadowing of the radar beam. The aspect of these flashes is explained by the fact that the sum of the contributions of the different parts of a blade is coherent only when the blade is perpendicular to the line of sight. If there is no perpendicularity, the vector sum is destructive, as a consequence of the variability of the phase. Just in the blade tip the vectors are not enough to cancel the signal and a peak 
appears. This peak is visible in Fig. 8, and as the blade describes a circumference, a sinusoidal function appears in the spectrogram.

Although the blades tip velocities can be much higher than the maximum non ambiguous velocity of approximately $18 \mathrm{~m} \cdot \mathrm{s}^{-1}$, the yaw angle involves a lower radial velocity.

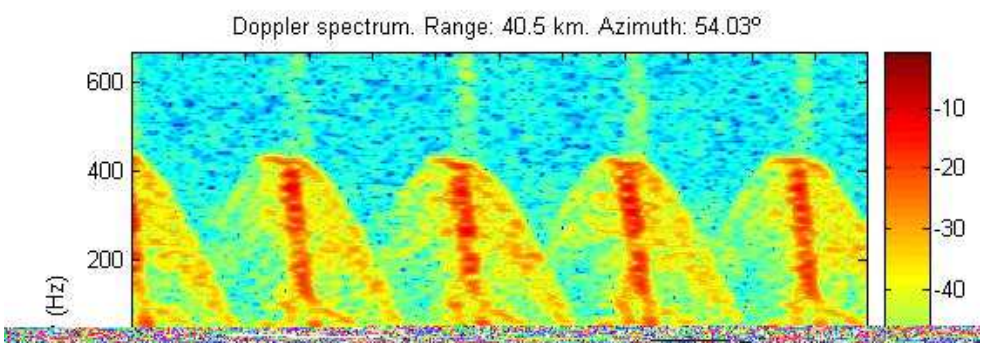

Fig. 8. Doppler spectrum at $42.5 \mathrm{~km}$ bin versus time.

In most cases the blade's energy returns are distributed over the entire Doppler frequency spectrum, there is a total ambiguity scheme, Fig. 9.

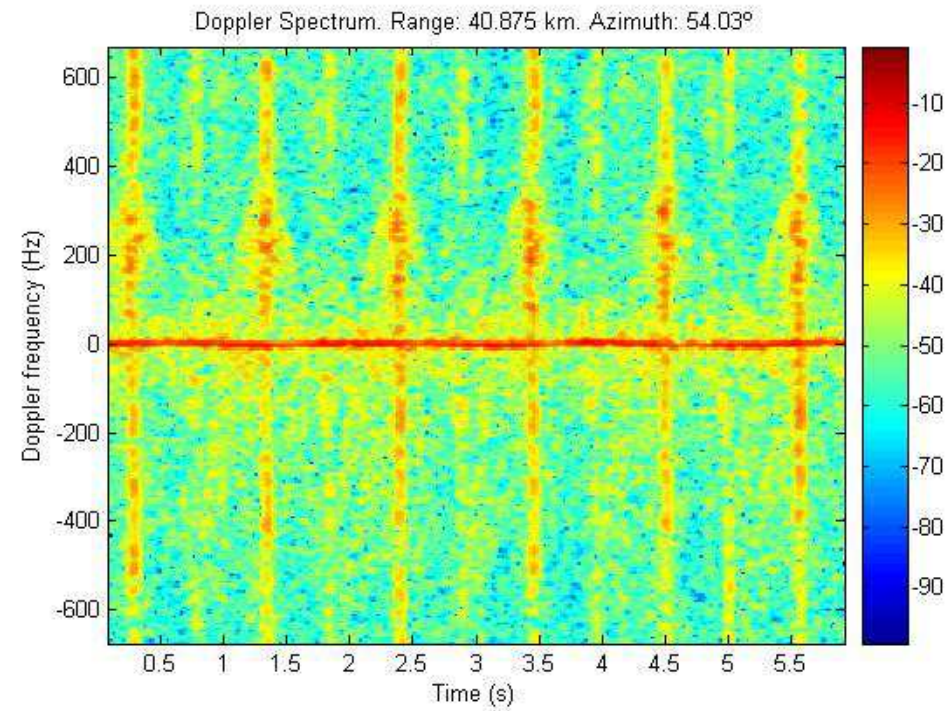

Fig. 9. Ambiguous WTC. 
Focusing on the most powerful flashes, the wind turbine whose time behaviour has been represented in Fig. 9 rotates at $20 \mathrm{rpm}$. But, what is the meaning of the weaker flashes between them? There are several possibilities. First, they can correspond to the same blades on a different position than the perpendicular as they seem to have the same period. Second, there is another wind turbine in the same range bin with apparently the same rotation rate. Third, and more probable, they are the effect of the antenna side lobes. Then, for most wind farms and wind turbines, not even the time between flashes will be completely clean of clutter. More examples of spotlight WTC are plotted in Fig. 10.

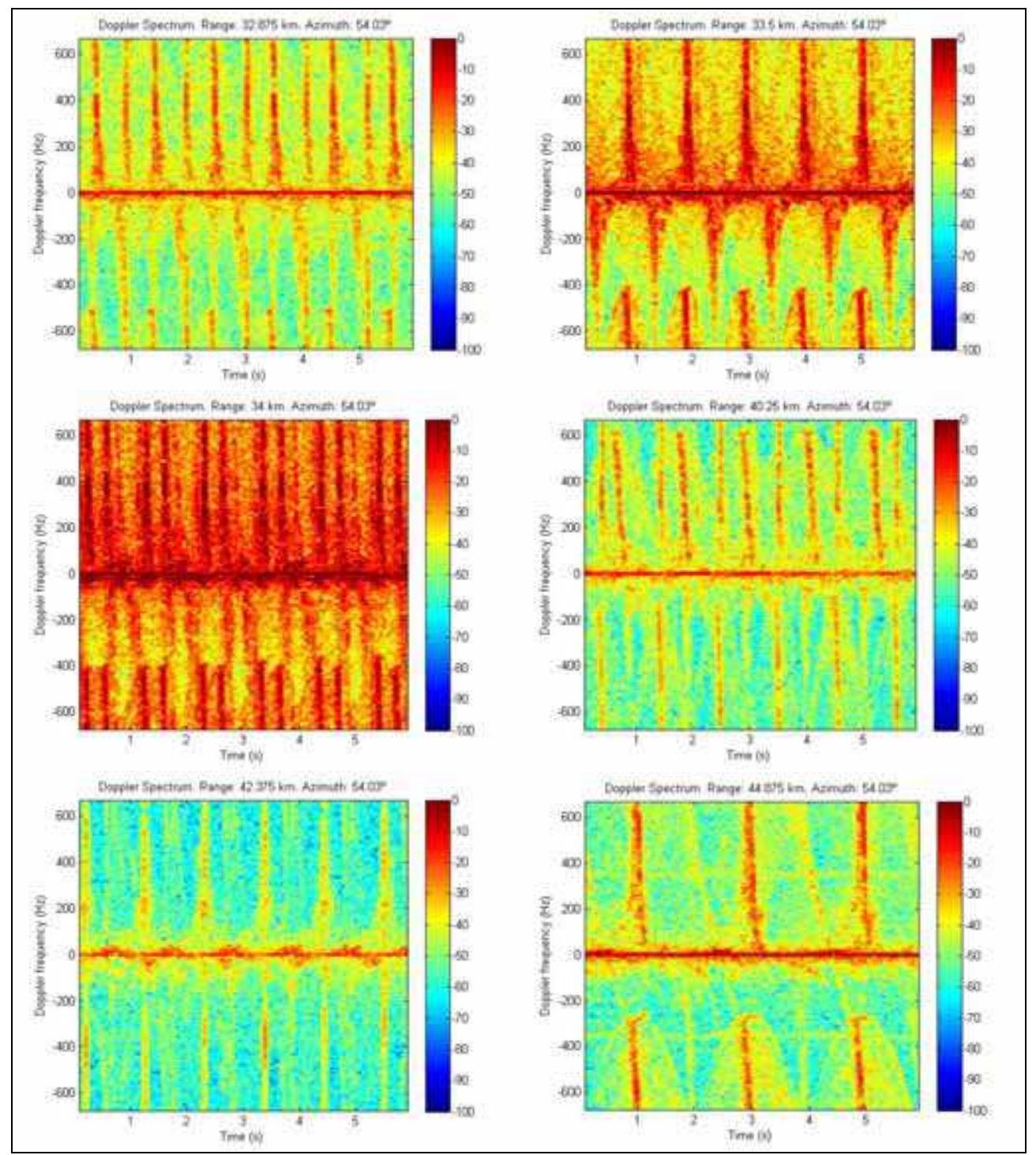

Fig. 10. Examples of WTC. 


\subsection{Statistics}

The aim of the characterization of wind turbine clutter by means of statistical analysis is to model it as a stochastic process. Although this kind of clutter is not strictly stationary, it may exhibit some features that would allow an optimal detection of wind turbines for a latter mitigation.

Doppler statistics

This section focuses on detailing the dynamic behaviour of the Doppler spectrum as well as the relationship between amplitude and spectral qualities (Gallardo-Hernando et al., 2008b). As it can be seen in Fig. 11, the amplitude variations follow the behaviour of the Doppler centroid, defined as the centre frequency of the Doppler spectrum of the data. Its most significantly variations take place at the same time the amplitude maximums appear. The Doppler Bandwidth is centred on $200 \mathrm{~Hz}$ and has very small variations.

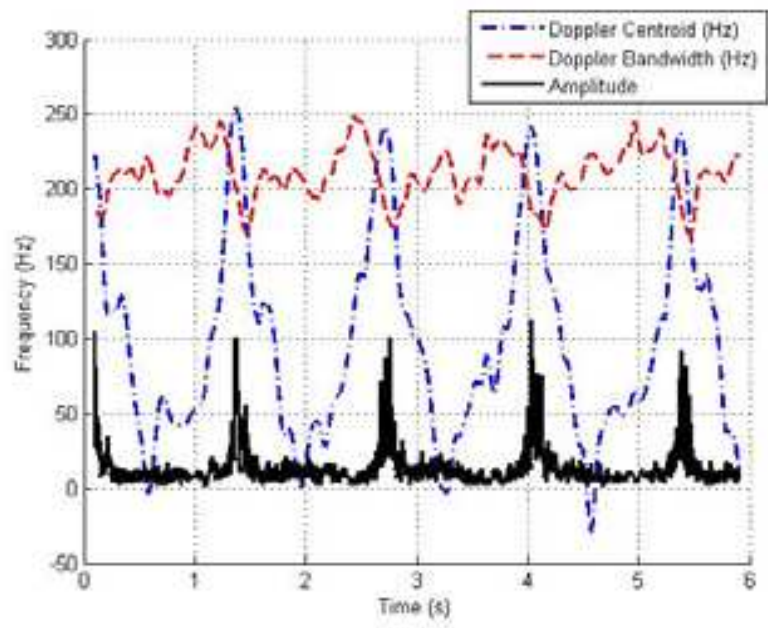

Fig. 11. Comparison of Doppler Centroid, Doppler Bandwidth and Amplitude of the signal versus time.

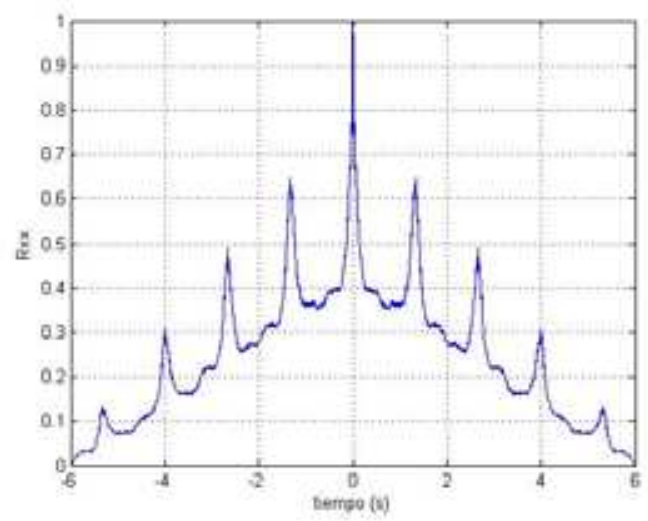

Fig. 12. Autocorrelation. 


\section{Amplitude statistics}

The autocorrelation of the signal in time, Fig. 12, confirms the periodicities we mentioned before, as a main lobe appear at 1.15 seconds.

A modelling of the experimental amplitude probability density function has also been done. This empirical PDF has been fitted to the Log Normal, Weibull, Rayleigh, Gamma and K distribution. We employed the maximum-likelihood method in all the distributions except for K, where we implemented the method of moments. Fig. 13 shows the result of the fitting process of the experimental PDF to the different theoretic functions. The $\mathrm{K}$ distribution seems to provide the best fit. In order to determine the best fit, another technique has been used. The experimental and theoretic moments of the distributions have been calculated from the fitting resulting parameters and then compared. The experimental moments are better approximated by the K distribution, Fig. 14 .

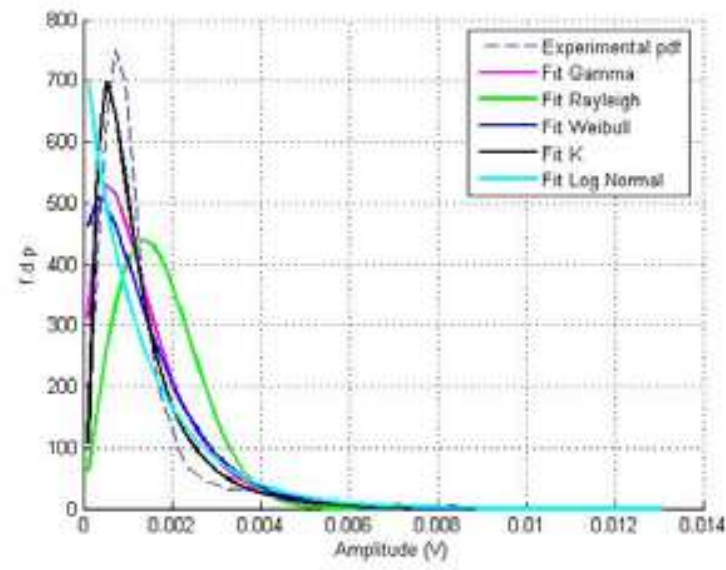

Fig. 13. Comparison of several distribution functions.

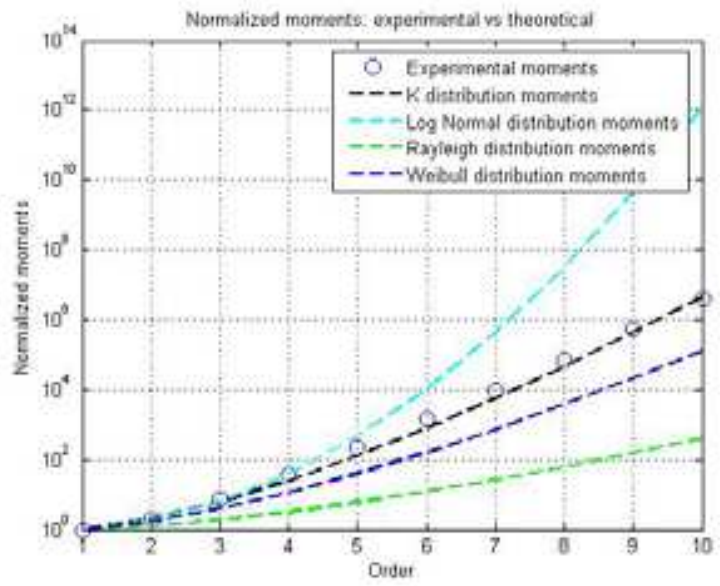

Fig. 14. Comparison of several distribution moments. 


\section{Mitigation concepts}

As it has been shown in previous sections, wind turbine clutter is unpredictable. It can fluctuate from one scan to the following. The blades rotate at such a rate to produce Doppler shifts on the order of 70 or even $90 \mathrm{~m} \cdot \mathrm{s}^{-1}$. These values can exceed the maximum nonambiguous Doppler velocity of some radars and then, make more difficult WTC detection and mitigation.

This section summarizes some of the mitigation techniques that have been published to date. These state-of-the-art processing techniques have been categorized in function of the affected radar: primary air surveillance radars and meteorological radars.

Apart from processing techniques, stealth solutions are also being studied to reduce the problem (Matthews et al., 2007). These techniques try to develop radar absorbing materials as well as to design new wind turbines with reduced radar cross section, preserving the efficiency of turbines in terms of electricity production and construction costs. The main inconvenient of these solutions is that the materials employed might be only efficient for very specific radar frequency bands.

\subsection{Air surveillance radars}

Several techniques can be employed to minimise the effect of signal blocking and ghost target appearance which wind turbines can provoke. Some of them are listed below (Perry $\&$ Biss, 2007) and (Sergey et al., 2008):

- Moving Target Detection (MTD) Doppler processing would reduce the magnitude of the blade returns separating the blade spectrum into Doppler increments.

- Range Averaging Constant False Alarm Reduction (CFAR) processing. Wind turbines provoke the detection threshold to rise, and then, the shadow effect appears. CFAR would then be applied for each Doppler increment from MTD and then anomalous power bins would be substituted with average noise power.

- Increased System Bandwidth would allow detections between wind turbines by using a higher resolution clutter map.

- Plot and Track Filters would reduce false alarms on returns with non-aircraft profiles.

- Range and Azimuth Gating (RAG) maps would enable unique mitigation algorithms to be implemented only in wind farm areas, maintaining normal performance outside the wind farms.

- Sensitivity Time Control (STC) would minimize the radar sensitivity at short range in order to limit the return from the wind turbine while not affecting target detection and so, prevent the receptor to be driven to saturation.

- $\quad$ Enhanced target tracking techniques can be used after detection. Feature aided tracker (FAT) identifies features from signals and process them in a probabilistic manner. The tracker would incorporate special processing techniques such us adaptive logic, map aided processing, processing priorization, enhanced tracking filters or classification algorithms.

These techniques can be used all together and, theoretically, they would allow the detection of aircrafts in wind farm areas with similar results in terms of detection and false alarm probabilities than in areas free from wind turbine clutter.

\subsection{Meteorological radars}

Weather radars are one of the most affected radio systems by wind turbine clutter. This radar is a special type of primary radar intended to measure atmospheric volumetric targets: 
large volumes of clouds and rain. The main distorting effects include reflections from the static parts, reflections from the rotating parts and shadowing or blocking (Greving \& Malkomes, 2008b). These effects cause the meteorological algorithms to fail and give false radar estimates of precipitation and wind velocity, as it can be seen in Fig. 15.

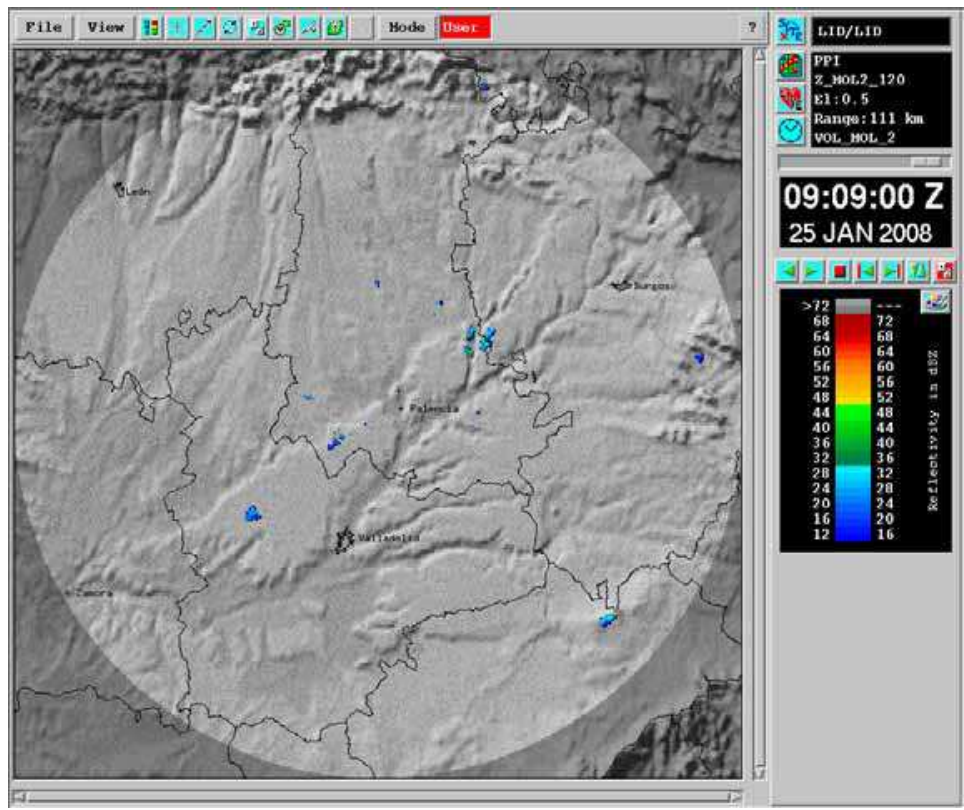

Fig. 15. PPI reflectivity image in a clear day. All the returns come from wind farms.

\section{Prevention}

Some of the mitigation efforts are focused on the prevention of this clutter (Donaldson et al., 2008). The assessment for new wind farms should be planned taking into account nearby weather radars by using line of sight calculations, standard 4/ 3 radio propagation model and echo statistics. But already built wind farms are still distorting weather radars, and then, specific processing is needed.

Interpolation

Wind turbine clutter spectrum usually exceeds most weather radar Doppler capacities. Current clutter filtering techniques are capable of removing the tower component effectively but the effects of the blade motion remains. The objective is to remove the blade components without distorting the desired weather signal. Some studies (Isom et al., 2007) propose interpolation techniques to mitigate WTC. These techniques use uncontaminated data to estimate the weather signal in bins which have been previously detected as contaminated. Results are plotted in Fig. 16. However large wind farms will cause an important loss of valuable weather information in their areas if the separation between turbines is narrower than twice the resolution distance, as none clean bins can be used.

Rain rate dependence

Interpolation has also been used in other works (Gallardo-Hernando et al.,2009) to show the dependence of this technique on rain rate variations. The study included simulated weather data as well as real clutter data retrieved from the radars described in section 3 . The 

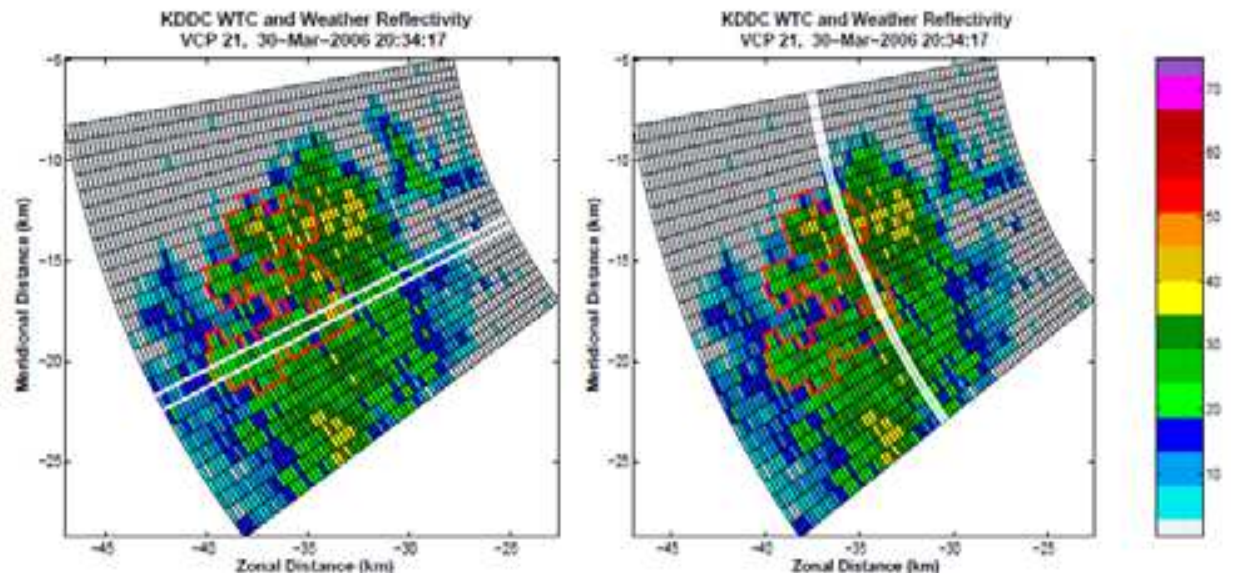

Fig. 16. Interpolation in PPI plots (Isom et al., 2007).

mitigation algorithm is based on the interpolation of correct values in the range bins which had been previously detected as contaminated by WTC. This interpolation is made in the direction of the velocity of the wind. The simulated rain Doppler spectrum was directly added to the WTC spectrum. Zero velocity clutter was previously removed. Fig. 17 shows the result of the addition of simulated rain spectrum to the WTC spectrum data in range plots. The estimated values of reflectivity, Fig. 17a, and velocity, Fig. 17b are drawn for all of the circumstances: WTC plus rain, simulated rain and corrected values. The simulated spectrum uses a rain intensity of $1 \mathrm{~mm} / \mathrm{h}$, which implies that the rain would be barely visible under the wind farms. The wind velocity does not vary with range. In reflectivity, the error drops from 32 to $4 \mathrm{~dB}$. In velocity, the error drops from 23 to $0.5 \mathrm{~m} / \mathrm{s}$.

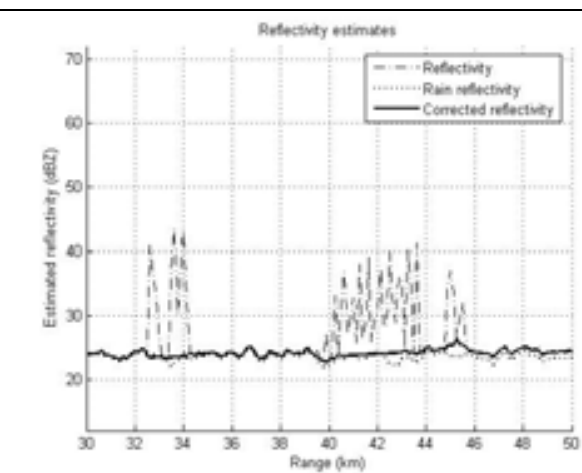

(a)

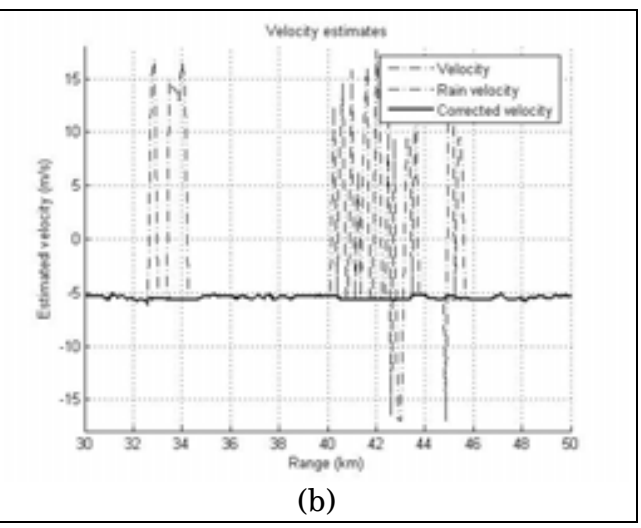

(b)

Fig. 17. Total, rain and corrected reflectivity and velocity values for $R=1 \mathrm{~mm} / \mathrm{h}$. In reflectivity, the error drops from 32 to $4 \mathrm{~dB}$. In velocity, the error drops from 23 to $0.5 \mathrm{~m} / \mathrm{s}$.

Rain Doppler spectra were simulated from $1 \mathrm{~mm} / \mathrm{h}$ to $70 \mathrm{~mm} / \mathrm{h}$ and used the same mitigation algorithm, with the previous detection of WTC contaminated range bins. The results are summarized in Fig. 18. Fig 18a shows the errors found in the reflectivity 
estimation, in $\mathrm{dB}$ before and after the algorithm. The error decreases almost exponentially as the rain intensity increases and there is a point where the error is almost the same using or not the algorithm. This happens when rain is much more powerful than clutter. Fig $18 \mathrm{~b}$ shows the errors found in the velocity estimation before and after applying the algorithm. In this case at certain rain intensity WTC stops affecting the estimation of reflectivity, and the error is slightly greater when using the algorithm due to the evident loss of information.

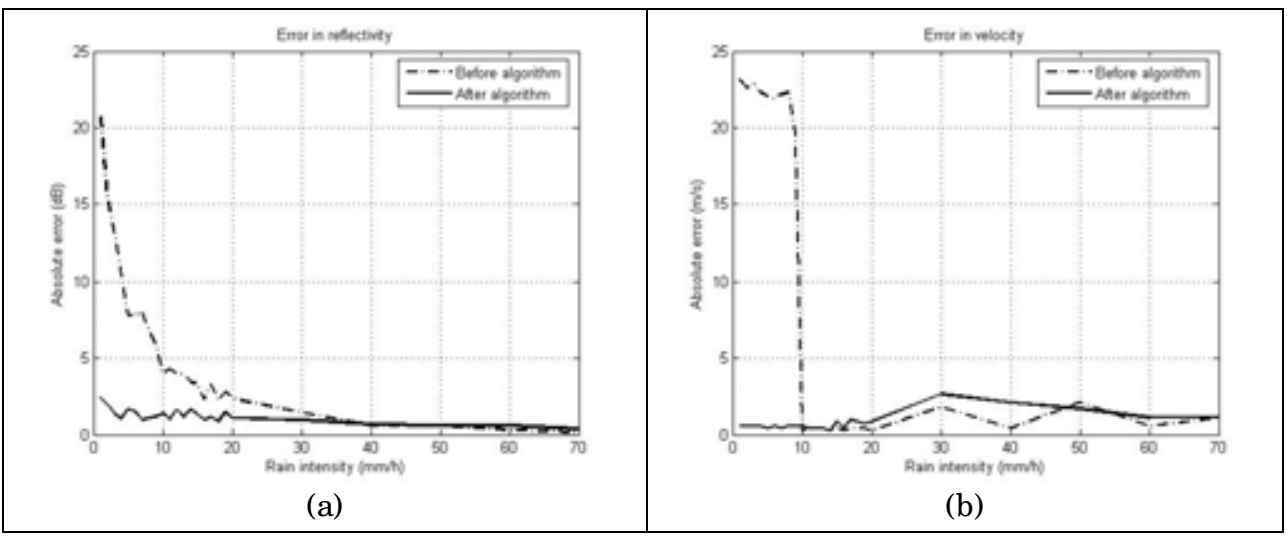

Fig. 18. Absolute error in reflectivity and velocity estimations.

\section{Adaptive thresholding}

As we have seen, these techniques require the previous detection of contaminated cells. However, it has also been shown that an adaptive detection can be applied in spotlight mode (Gallardo-Hernando et al., 2008c). This technique is based on the removal of flashes by means of adaptive thresholding. In Fig 19a a real WTC spotlight spectrum can be observed. Flashes are spread over the entire spectrum. Fig. 19b shows a spectrogram of the addition of real wind turbine spectrum and simulated $5 \mathrm{~mm} / \mathrm{h}$ variable velocity rain spectrum.

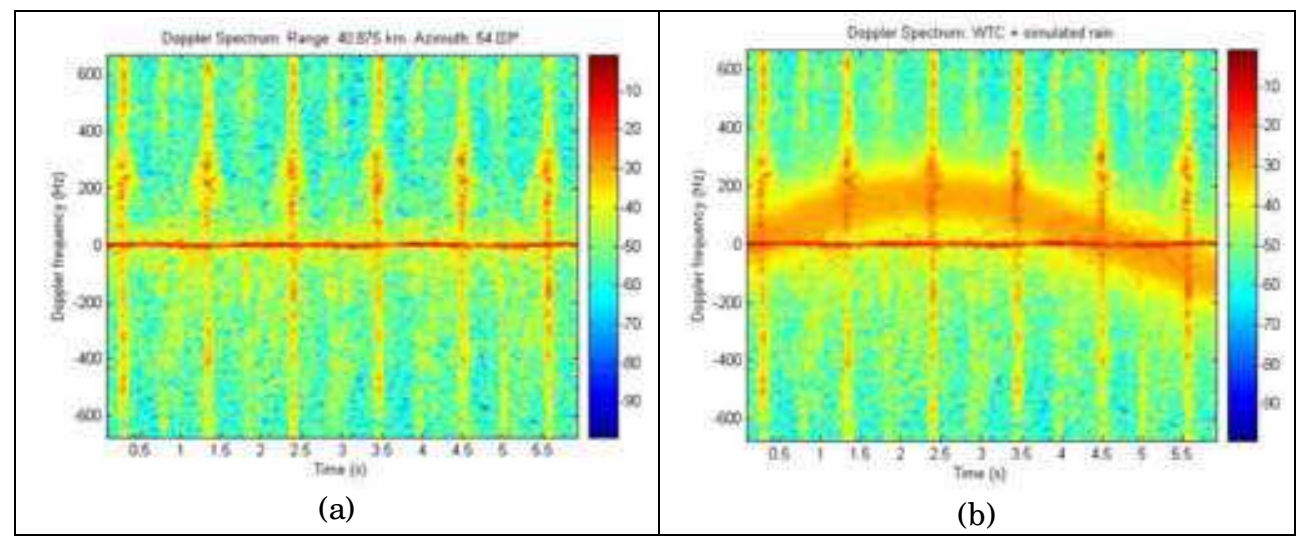

Fig. 19. WTC spotlight data spectrum and its addition to simulated weather data. 
The election of an appropriate threshold has to be made regarding the significant changes in the amplitude of the signal, Fig. 20a. Finally, Fig. 20b shows the results after the flashes detection, removal and replacement with information of adjacent time bins.

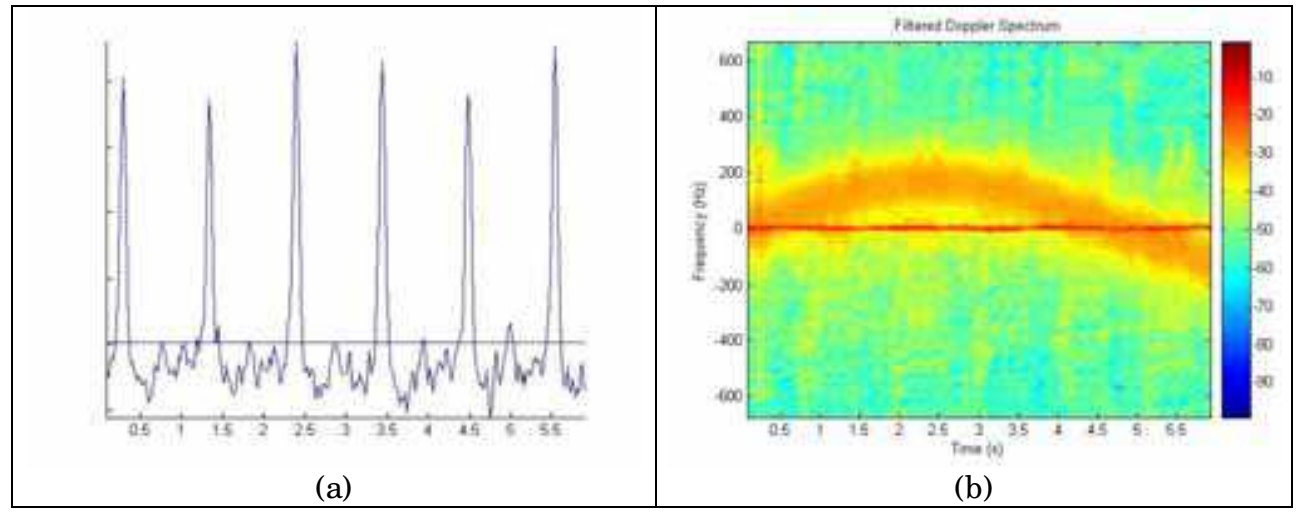

Fig. 20. Adaptive thresholding.

\section{Tomographic techniques}

In (Gallardo-Hernando et al., 2008a), an image processing technique to remove WTC in spotlight operation mode is presented. If Fig. $19 \mathrm{~b}$ is considered as an image, it can be handled by means of specific image processing. The Radon transform of an image is calculated by integrating the intensity values among straight lines characterized by an angle and a distance. Therefore the vertical lines in the original image are going to be seen as $0^{\circ}$ points in the Radon domain, as they only appear at $0^{\circ}$ integrations. In particular, variations of $0.1^{\circ}$ were used in a $-90^{\circ} \leq \theta<90^{\circ}$ interval. Fig. 21a shows the result of the transformation of Fig. 19b into the Radon domain. The six clutter flashes that appeared before are now six $0^{\circ}$ points, whereas the rain is mostly near $90^{\circ}$, as well as the ground clutter. WTC is now very easy to remove without distorting the weather information, in this case, values between $5^{\mathrm{o}} \leq \theta<5^{\mathrm{o}}$ were filtered. Fig. $21 \mathrm{~b}$ shows the results after the removal of the clutter points and the inverse transformation.

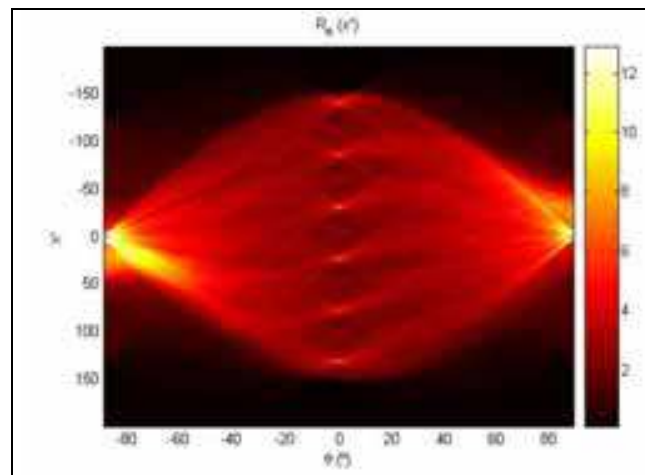

(a)

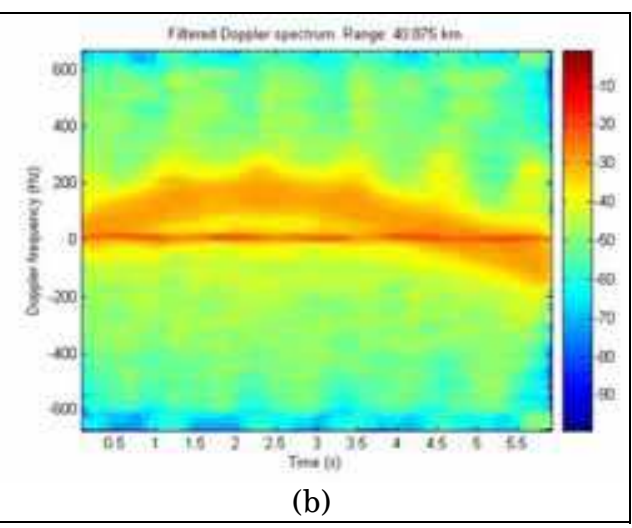

(b)

Fig. 21. Radon transformation and results after filtering. 


\section{Adaptive Arrays}

Adaptive phased array radars have also been proposed as possible solution to WTC in weather radars (Palmer et al., 2008). These arrays offer the capability to obtain a signal that accurately represents the weather only scattering field. By carefully using the interfence of the radiation pattern, the WTC near the ground is rejected while the scattered energy of the weather above the ground is preserved.

\section{Conclusion}

In this chapter the main effects of wind turbines on the performance of radar systems have been explained. The radar signature of wind turbine clutter is unique and then, it requires a special treatment when developing mitigation techniques. WTC clutter remains spatially static, but it fluctuates continuously in time. In surveillance radars the return from wind turbines can be completely different from one scan to the following. In addition, apart from the powerful tower return, the movement of blades produces large Doppler shifts. Some of the latest mitigation techniques have been described; however, a more extensive study has to be accomplished. As future research, novel automatic detection techniques as well as accurate mitigation schemes in scanning radars have been planned to be developed.

\section{References}

Donaldson, N.; Best, C. \& Paterson, B. (2008). Development of Wind Turbine Assessments for Canadian Weather Radars. Proceedings of the Fifth European Conference on Radar in Meteorology and Hydrology, ERAD 2008, pp. 1-4, Helsinki, Finland, July 2008. ISBN: 978-951-697-676-4.

Doviak, R. J., \& Zrnic, D. S. (1984). Doppler Radar and Weather Observations, Academic Press, Inc., ISBN: 0-12-1420-X. Orlando, Florida. USA.

Freris, L. (1992). Inherit the Wind. IEEE Review, Vol. 38, No. 2, April 1992, pp. 155-159. ISSN: 0953-5683.

Gallardo-Hernando, B.; Pérez-Martínez, F. \& Aguado-Encabo, F. (2008a). Characterization Approach of Wind Turbine Clutter in the Spanish Weather Radar Network. Proceedings of the Fifth European Conference on Radar in Meteorology and Hydrology, ERAD 2008, pp. 1-5, Helsinki, Finland, July 2008. ISBN: 978-951-697-676-4.

Gallardo-Hernando, B.; Pérez-Martínez, F. \& Aguado-Encabo, F. (2008b). Statistical Characterization of Wind Turbine Clutter in C-band Radars. Proceedings of the 2008 International Conference on Radar, pp. 360-364, Adelaide, Australia, September 2008. ISBN: 978-1-4244-2321-7.

Gallardo-Hernando, B.; Pérez-Martínez, F. \& Aguado-Encabo, F. (2008c). La Energía Eólica y su Impacto en la Red de Radares Meteorológicos de la AEMet. XXIII Simposium Nacional de la Unión Científica Internacional de Radio, pp. 1-4, Madrid, Spain, September 2008. ISBN: 978-84-612-6291-5.

Gallardo-Hernando, B.; Pérez-Martínez, F. \& Aguado-Encabo, F. (2009). Mitigation of Wind Turbine Clutter in C-band Weather Radars for Different Rainfall Rates. Proceedings of the 2008 International Conference on Radar, ISBN: 2-912328-55-1 pp. 1-6, Bordeaux, France, October 2009.

Gamesa. G58-850 Turbine http:/ / www.gamesa.es/ index.php/ es/ aerogeneradores

Greving, G. \& Malkomes, M. (2008a). Application of the Radar Cross Section RCS for Objects on the Ground - Example of Wind Turbines. Proceedings of the 2008 
International Radar Simposium, pp. 1-4, Wroclaw, Poland, May 2008. ISBN: 978-837207-757-8.

Greving, G.; \& Malkomes, M. (2008b). Weather Radar and Wind Turbines - Theoretical and Numerical Analysis of the Shadowing Effects and Mitigation Concepts. Proceedings of the Fifth European Conference on Radar in Meteorology and Hydrology, ERAD 2008, pp. 1-5, Helsinki, Finland, July 2008. ISBN: 978-951-697-676-4.

Hatziargyriou, N.; \& Zervos, A. (2001). Wind Power Development in Europe. Proc. IEEE, Vol. 89, no. 12, December 2001, pp. 1765-1782, ISSN: 0018-9219.

Isom, B. M.; Palmer, R. D.; Secrest, G. S.; Rhoton, R. D.; Saxion, D.; Winslow, J. L.; Reed, J; Crum, T.; \& Vogt, R. (2007). Characterization and mitigation of wind turbine clutter on the WSR-88D network. Proceedings of the 33rd Conference on Radar Meteorology, August 2007, paper 8B.8.

Isom, B. M. (2007b). Characterization and Mitigation of Wind turbine Clutter for the WSR88D Network. University of Oklahoma.

Jackson, C. A. (2007). Wind farm characteristics and their effect on radar systems. Proceedings of the 2007 IET International Conference on Radar Systems, pp. 1-6, Edinburg, UK, October 2007, IET. ISBN: 978-0-86341-848-8

Jenkins, N. (1993): 'Engineering wind farms', Power Engineering Journal, Volume 7 Issue 2. April 1993. pp. 53-60. ISSN: $1479-8344$

Matthews, J.; Pinto, J. \& Sarno, C. (2007). Stealth Solutions to solve the radar-wind farm interaction problem. Proceedings of the 2007 Antennas and Propagation Conference, pp. 101-104, Loughborough, UK, April 2007, IEEE. ISBN: 1-4244-0776-1

Palmer, R. D.; Le, K. D. \& Isom, B. (2008). Wind Turbine Clutter Mitigation using Fully Adaptive Arrays. Proceedings of the $5^{\text {th }}$ European Radar Conference, pp. 356-359, Amsterdam, The Netherlands, October 2008. ISBN: 978-2-87487-009-5.

Perry, J. \&Biss, A. (2007). Wind farm clutter mitigation in air surveillance radar. Aerospace and Electronic systems Magazine, IEEE, Vol. 22, No. 7, July 2007, pp. 35-40. ISSN: 0885-8985.

Poupart, G. (2003). Wind Farms Impact on Radar Aviation Interests. Final report. QinetiQ W/ 14/ 00614/ 00/ REP DTI PUB URN 03/ 1294., 2003.

Sergey, L.; Hubbard, O; Ding, Z.; Ghadaki, H.; Wang, J. \& Ponsford, T. (2008). Advanced mitigating techniques to remove the effects of wind turbines and wind farms on primary surveillance radars. Proceedings of the 2008 IEEE Conference, pp. 1-6, Rome, Italy, May 2008. ISBN: 978-1-4244-1538-0.

Theil, A. \& van Ewijk, L.J. (2007). Radar Performance Degradation due to the Presence of Wind Turbines. Proceedings of the 2007 IEEE Radar Conference, pp. 75-80, Boston, USA, April 2007. ISBN: 1-4244-0284-0.

Thresher, R.; Robinson, M.; \& Veers, P. (2007). To Capture the Wind. IEEE Power energy Mag. Vol. 5, No. 6, December 2007, pp. 34-46. ISSN: 1540-7977.

Vogt, R.; Reed, J.; Crum, T.; Snow, J.; Palmer, R.; Isom, B. \& Burgess, D. (2008). Impacts of wind farms on WSR-88D operations and policy considerations. Preprints, 23rd Int. Conf. on Interactive Information Processing Systems (IIPS) for Meteorology, Oceanography, and Hydrology, San Antonio, TX, Amer. Meteor. Soc., Paper 5B.7.

World Wind Energy Association (2009). "World Wind Energy Report 2008". Report. http:/ / www.wwindea.org/ home/ images/ stories/ worldwindenergyreport2008_s. pdf. Retrieved on 16-May-2009. 
Edited by Guy Kouemou

ISBN 978-953-307-029-2

Hard cover, 410 pages

Publisher InTech

Published online 01, January, 2010

Published in print edition January, 2010

In this book "Radar Technology", the chapters are divided into four main topic areas: Topic area 1: "Radar Systems" consists of chapters which treat whole radar systems, environment and target functional chain. Topic area 2: "Radar Applications" shows various applications of radar systems, including meteorological radars, ground penetrating radars and glaciology. Topic area 3: "Radar Functional Chain and Signal Processing" describes several aspects of the radar signal processing. From parameter extraction, target detection over tracking and classification technologies. Topic area 4: "Radar Subsystems and Components" consists of design technology of radar subsystem components like antenna design or waveform design.

\section{How to reference}

In order to correctly reference this scholarly work, feel free to copy and paste the following:

Beatriz Gallardo-Hernando, Félix Pérez-Martínez and Fernando Aguado-Encabo (2010). Wind Turbine Clutter, Radar Technology, Guy Kouemou (Ed.), ISBN: 978-953-307-029-2, InTech, Available from: http://www.intechopen.com/books/radar-technology/wind-turbine-clutter

\section{INTECH}

open science | open minds

\section{InTech Europe}

University Campus STeP Ri

Slavka Krautzeka 83/A

51000 Rijeka, Croatia

Phone: +385 (51) 770447

Fax: +385 (51) 686166

www.intechopen.com

\section{InTech China}

Unit 405, Office Block, Hotel Equatorial Shanghai

No.65, Yan An Road (West), Shanghai, 200040, China

中国上海市延安西路65号上海国际贵都大饭店办公楼405单元

Phone: +86-21-62489820

Fax: +86-21-62489821 
(C) 2010 The Author(s). Licensee IntechOpen. This chapter is distributed under the terms of the Creative Commons Attribution-NonCommercialShareAlike-3.0 License, which permits use, distribution and reproduction for non-commercial purposes, provided the original is properly cited and derivative works building on this content are distributed under the same license. 